\title{
Stereotactic Radiosurgery after Subtotal Resection of Critically-Located Grade I Meningioma: A Single-Center Experience and Review of Literature
} \author{
Memduh KAYMAZ2, Sukru AYKOL ${ }^{2}$, Hakan EMMEZ ${ }^{2}$ \\ ${ }^{1}$ Cubuk Halil Sivgin State Hospital, Department of Neurosurgery, Ankara, Turkey \\ ${ }^{2}$ Gazi University Faculty of Medicine, Department of Neurosurgery, Ankara, Turkey \\ ${ }^{3}$ Atilim University Faculty of Medicine, Department of Neurosurgery, Ankara, Turkey
}

Burak KARAASLAN ${ }^{1,2}$, Emrah CELTIKCl ${ }^{2}$, Erkut Baha BULDUK ${ }^{3}$, Alp Ozgun BORCEK $^{2}$, Gokhan KURT²,

Corresponding author: Burak KARAASLAN burakkaraaslan08@hotmail.com

\section{ABSTRACT}

AIM: To analyze the results of stereotactic radiosurgery in 295 patients with residual Grade I meningiomas located at parasellar region, petroclival region, cerebellopontine angle and parasagittal region.

MATERIAL and METHODS: A total of 295 patients with Grade 1 residual Meningiomas (197 women, 98 men), who were treated by adjuvant radiosurgery in Gazi University Gamma Knife Center between 2004-2015 were analyzed. WHO Grade 2 and 3 meningiomas were not included in our study. Minimum radiological follow-up was 24 months. The median follow-up was 54 months. The tumor volume, location, treatment dose, morbidity, progression free survival and tumor control rate were analyzed.

RESULTS: The median tumor volume was $5.2 \mathrm{~cm}^{3}$ (0.04-39.7), median age was 50 (20-80), median dose was 14 Gy and tumor control rate was $94.5 \%$ (stationary in $85.0 \%$, volume reduction in 9.5\%). Increase in tumor volume was seen in 16 patients (5.5\%) and re-operation was performed in 5 of them (1.6\%). Stereotactic radiosurgery was performed again for 8 patients $(2.7 \%)$. The location of the tumors was as follows: $39.3 \%$ parasellar region, $20 \%$ cerebellopontine angle, $13.6 \%$ petroclival and $27.1 \%$ was parasagittal, falcine or convexity. Major morbidities were detected in $6(2 \%)$ patients. Minor morbidities were detected in 18 (6.1\%) patients.

CONCLUSION: Stereotactic radiosurgery is an effective and safe treatment modality for residual Grade I meningiomas.

KEYWORDS: Benign meningioma, Radiosurgery, Cavernous sinus, Petroclival, Cerebellopontine angle

\section{INTRODUCTION}

$\mathrm{H}$ arvey Cushing first used the term 'meningioma' in 1922 (5). Today, the most frequent primary brain tumors are meningiomas which originate from arachnoid cap cells $(14,34)$. Meningiomas constitute $24 \%-33 \%$ of primary brain tumors; and $75-90 \%$ of meningiomas are histologically classified as WHO Grade I which are benign and slow-growing lesions $(62,65)$. Although WHO Grade I meningiomas are benign pathological entities, growth rates may be different among patients (12).

Microsurgical resection represents the first line treatment for symptomatic and large meningiomas. If Simpson Grade I resection (total resection of tumor, and the associated dura and bone) can be achieved, the recurrence rate is significantly low (58). Close relationship of the tumors to the cranial nerves, brain stem, arteries, and venous structures makes resection
Burak KARAASLAN (D): 0000-0003-1015-396X

Emrah CELTIKCI (D): 0000-0001-5733-7542

Erkut Baha BULDUK (1) : 0000-0002-8812-1290
Alp Ozgun BORCEK (1) : 0000-0002-6222-382X

Gokhan KURT (D) : 0000-0002-2773-056X

Memduh KAYMAZ (D): 0000-0003-2165-3273
Sukru AYKOL (1) : 0000-0001-7896-1563

Hakan EMMEZ (D) : 0000-0002-3290-179X 
difficult and decrease the extent of resection (EOR). That is why the morbidity and mortality increase with the EOR especially in skull base located meningiomas (5).

We aim to analyze the efficacy of Stereotactic Radiosurgery (SRS) for residual WHO Grade I meningiomas as all of the tumors were histologically confirmed. This study also provides objective information about the efficacy of SRS on WHO Grade I meningiomas in critical location of the cranium. The tumor control rates, morbidity rates, outcome predictors of SRS were analyzed for residual meningiomas.

\section{MATERIAL and METHODS}

\section{Study Design}

A total of 1262 meningioma patients were treated in Gazi University Gamma Knife Center between 2004 and 2015. A total of 367 patients (29\%) had undergone prior surgery and the histopathological diagnosis was Grade I meningioma. Totally 295 patients (197 women, 98 men) with Grade I meningiomas were reviewed retrospectively (Figure 1). Demographic characteristics and SRS treatment parameters of study are detailed in Table I. The median follow up was 54 months. The location, volume, dose, morbidities and response rates were analyzed.

\section{Radiosurgical Technique}

The details of the treatment protocols were explained previously (6). The Gamma Knife Model C and Perfexion were used. The treatment starts with the Leksell G Frame (Elekta AB) application under local anesthesia and sedation if needed. High-resolution stereotactic Magnetic Resonance Imagining (MRI) was performed and $1 \mathrm{~mm}$ slice axial T2-weighted and T1-weighted contrast enhancement images were obtained after placement of the frame. Radiosurgical treatment was planned by our radiosurgery team (neurosurgeon, radiation oncologist and medical physicist) using Gamma Plan (Elekta $A B)$.

\section{Clinical and Radiological Follow-Up}

Clinical and radiological follow-up were usually performed at 3 , 6, 12, 18 and 24 months after the treatment. After 24 months, the patients with stable tumors were followed-up on an annual basis. Follow-up examinations were performed in Gazi University Gamma Knife Center. Neurological examinations were compared with findings at the day of radiosurgical

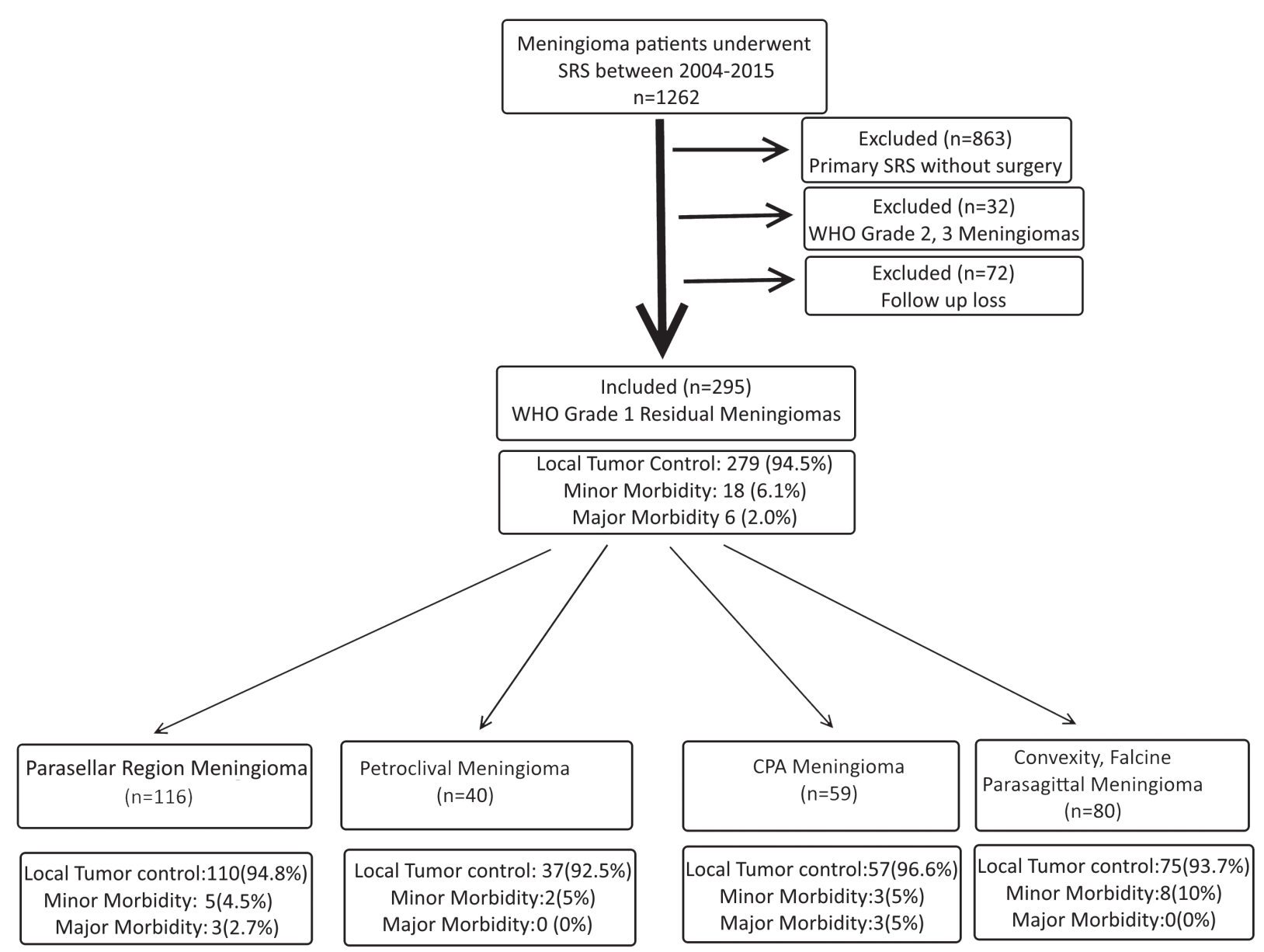

Figure 1: Flow diagram showing patient selection and summary of the outcomes of the study. 
treatment. Follow-up MRI scans were compared with the MRI images obtained at the time of the treatment. Enlargement of tumor in any of the three planes was defined as tumor growth.

\section{Statistical Analysis}

Progression-free survival was defined as the stationary tumor or decrease of the tumor volume in the $36,48,60$ and 96-month follow-up. Local tumor control was defined as the stationary tumor or decrease of the tumor volume in the last radiological follow-up. New onset cranial nerve findings, radiation-induced necrosis, radiation-induced symptomatic edema, decreased visual acuity and motor weakness were considered as major morbidities. Transient edema, headache, numbness and dizziness after SRS were considered as minor morbidity.

The descriptive statistics were carried out in all series and in all subgroups for all the parameters (Table I, II). In the multivariate statistical studies, the impacts of age, gender, localization, treatment doses, and tumor volume on posttreatment progression and on morbidity were examined in all series and subgroups. The Kaplan-Meier Analysis was made for survival without progression in $36,48,60$ and $96^{\text {th }}$ months.

\section{RESULTS}

\section{Patient and Tumor Characteristics}

The mean follow-up period was 54 months (24-106). The mean follow-up period was 52.2 months for the meningiomas that were localized in the convexity, falcine and parasagittal areas. In the petroclival, parasellar region and CPA meningiomas, the mean follow-up period was 56.6, 56.4 and 49.7 months.

The mean age was $50(20-80)$ in all patient series. The female gender was dominant in gender distribution in all series and subgroups. In the gender distribution, a total of 197 (66.8\%) patients were female, and 98 (33.2\%) patients were male.

Mean tumor volume was $5.2 \mathrm{~cm}^{3}(0.04-.39 .7)$. The number of patients who had tumor volume as $<4 \mathrm{~cm}^{3}, 4-10 \mathrm{~cm}^{3}$ and
$>10 \mathrm{~cm}^{3}$ was 110,108 and 77 , respectively $(37.3 \%, 36.6 \%$, $26.1 \%)$. Mean tumor volumes in the meningiomas that were localized in the convexity, falcine and parasagittal areas were $7.2 \mathrm{~cm}^{3}$. Mean tumor volumes in Petroclival, Parasellar and CPA meningiomas were $5.0 \mathrm{~cm}^{3}, 9.0 \mathrm{~cm}^{3}$ and $7.0 \mathrm{~cm}^{3}$, respectively.

Average treatment dose was 14 Gy (12-22 Gy). Average treatment dose for the meningiomas that were localized in the convexity, falcine and parasagittal areas was 15.2 Gy. Average treatment doses in Petroclival, Parasellar and CPA meningioma were 13.9 Gy, 14.0 Gy and 14.2 Gy, respectively. The number of patients whose treatment doses were $<15$ Gy and $\geq 15$ Gy was $182(61.7 \%)$ and $113(38.3 \%)$, respectively. The descriptive statistics in all series and subgroups are summarized in Tables I and II.

\section{Radiological and Clinical Outcome}

The tumor control rate was $94.5 \%$ in mean 54 months of radiological and clinical follow-up period. The number of patients in whom tumor progression was detected was $16(5.5 \%)$ in the latest radiological follow-up. Although the tumor volume remained stable in $251(85 \%)$ patients in the radiological follow-up, and tumor volume decreased in $28(9.5 \%)$ patients. The tumor control rate was $93.7 \%$ in convexity, falcine and parasagittal meningioma subgroup. In Petroclival, Parasellar and CPA meningioma subgroups the tumor control rates were $92.5 \%, 94.8 \%$ and $96.6 \%$, respectively. The summary of clinical and radiological results after SRS is given in Table III.

A total of $210(71.2 \%)$ patients received 1 surgery; 67 (22.7\%) patients received 2 surgeries; and $18(6.1 \%)$ patients received 3 or more surgeries before SRS. The PFS in $36,48,60$ and $96^{\text {th }}$ months was $100 \%, 97 \%, 93 \%$ and $72 \%$, respectively (Figure 2). Five patients of those who had progression after SRS were re-operated and 8 patients received SRS again. No other treatment was applied to other patients because they did not accept further treatment. The number of patients who developed minor morbidities following SRS was 18

Table I: Demographic Characteristics and SRS Treatment Parameters of Study and Subgroups

\begin{tabular}{|c|c|c|c|c|c|c|}
\hline & & $\begin{array}{c}\text { Convexity, Falcine, } \\
\text { Parasagittal } \\
\text { n=80 (\%) }\end{array}$ & $\begin{array}{c}\text { Petroclival } \\
n=40(\%)\end{array}$ & $\begin{array}{l}\text { Parasellar } \\
n=116(\%)\end{array}$ & $\begin{array}{c}\text { CPA } \\
n=59(\%)\end{array}$ & $\begin{array}{c}\text { Overall } \\
\mathrm{n}=295(\%)\end{array}$ \\
\hline \multirow{2}{*}{ Gender } & Female & 42 (21.3) & $31(15.7)$ & $76(38.6)$ & $48(24.4)$ & 197 (100) \\
\hline & Male & $38(38.2)$ & $9(9.2)$ & $40(40.8)$ & $11(11.2)$ & $98(100)$ \\
\hline \multirow{2}{*}{ Age } & $<65$ & $71(26.4)$ & $36(13.4)$ & $110(40.9)$ & 52 (19.3) & 269 (100) \\
\hline & $\geq 65$ & $9(34.6)$ & $4(15.4)$ & $6(23.1)$ & $7(26.9)$ & 26 (100) \\
\hline \multirow{3}{*}{$\begin{array}{l}\text { Tumor volume } \\
\left(\mathrm{cm}^{3}\right)\end{array}$} & $<4$ & 31 (28.2) & $25(22.7)$ & $28(25.5)$ & $26(23.4)$ & $110(100)$ \\
\hline & $4-10$ & $30(27.8)$ & $8(7.4)$ & $50(46.3)$ & 20 (18.5) & $108(100)$ \\
\hline & $>10$ & $19(24.7)$ & $7(9.1)$ & $38(49.4)$ & 13 (16.9) & 77 (100) \\
\hline \multirow{2}{*}{ Median Dose } & $<15$ & $32(17.6)$ & $27(14.8)$ & $84(46.2)$ & $39(21.4)$ & $182(100)$ \\
\hline & $\geq 15$ & $48(42.5)$ & $13(11.5)$ & $32(28.3)$ & $20(17.7)$ & $113(100)$ \\
\hline
\end{tabular}


Karaaslan B. et al: Radiosurgery for Residual Meningiomas

Table II: Statistical Analyses of Demographic Characteristics

\begin{tabular}{lcccc}
\hline & Volume $\left(\mathbf{c m}^{\mathbf{3}}\right)$ & Age & Follow-up (Months) & Dose (Gy) \\
\hline Median & 5.2000000 & 50.00 & 54.00 & 14.0000 \\
\hline Mean & 7.6089192 & 48.91 & 53.98 & 14.3826 \\
\hline Std. Deviation & 6.89106796 & 11.818 & 25.273 & 1.56559 \\
\hline Minimum & .04300 & 20 & 24 & 12.00 \\
\hline Maximum & 39.70000 & 80 & 106 & 22.00 \\
\hline
\end{tabular}

Table III: Follow Up Results of Study and Subgroups

\begin{tabular}{|c|c|c|c|c|c|c|}
\hline & & $\begin{array}{c}\text { Convexity, } \\
\text { Falcine, } \\
\text { Parasagittal } \\
\mathrm{n}=80(\%)\end{array}$ & $\begin{array}{c}\text { Petroclival } \\
n=40(\%)\end{array}$ & $\begin{array}{l}\text { Parasellar } \\
n=116(\%)\end{array}$ & $\begin{array}{c}\text { CPA } \\
n=59(\%)\end{array}$ & $\begin{array}{c}\text { Overall } \\
\mathrm{n}=295(\%)\end{array}$ \\
\hline \multirow{3}{*}{$\begin{array}{l}\text { Radiological } \\
\text { Follow-up } \\
\text { (Tumor volume) }\end{array}$} & Regression & $6(21.4)$ & $2(7.1)$ & $13(46.4)$ & $7(25.0)$ & $28(100)$ \\
\hline & Stable & $69(27.5)$ & 35 (13.9) & 97 (38.6) & 50 (19.9) & $251(100)$ \\
\hline & Progression & $5(31.3)$ & $3(18.8)$ & $6(37.5)$ & $2(12.5)$ & $16(100)$ \\
\hline \multirow{4}{*}{$\begin{array}{l}\text { Clinical } \\
\text { Follow-up }\end{array}$} & None & 72 (26.6) & 38 (14.0) & 108 (39.9) & 53 (19.6) & $271(100)$ \\
\hline & Minor Morbidity & $8(44.4)$ & $2(11.1)$ & $5(27.8)$ & $3(16.7)$ & $18(100.0)$ \\
\hline & Major Morbidity & $0(0.0)$ & $0(0.0)$ & $3(50.0)$ & $3(50.0)$ & $6(100.0)$ \\
\hline & Total Morbidity & $8(33.3)$ & $2(8.3)$ & $8(33.3)$ & $6(25.0)$ & $24(100.0)$ \\
\hline
\end{tabular}

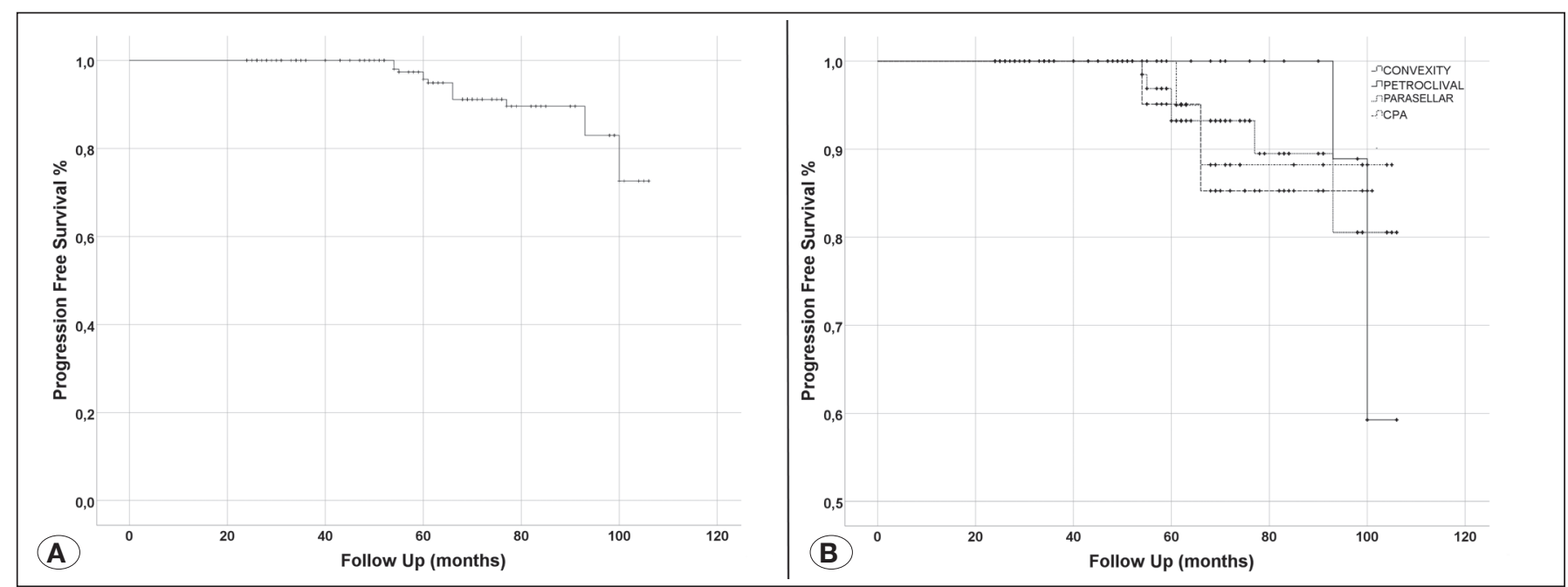

Figure 2: Kaplan-Meier analyses of actuarial progression free survival (PFS). A)The overall 36-, 48-, 60- and 96-month actuarial progression free survival (PFS) rates were 100\%, 97\%, 93\% and $72 \%$, respectively. B) There were no significant differences among patients' progression-free survival regarding the location of the tumor.

(6.1\%); and that of those who developed major morbidities was 6 (2\%). The radiologic and clinical follow-up results following SRS are summarized in Table III. The most common morbidities following SRS were headache at a rate of $3 \%$ $(n=9)$ and dizziness at a rate of $1.3 \%(n=4)$. Other most common morbidities were numbness $1 \%(n=3)$ and cranial nerve findings $1.3 \%(n=4)$. Decreases were detected in visual acuity in 2 patients, facial paralysis appeared in 1 patient, and trigeminal neuralgia was detected in 1 patient following SRS. No radiation-induced-secondary tumors were detected in any patients following SRS. 


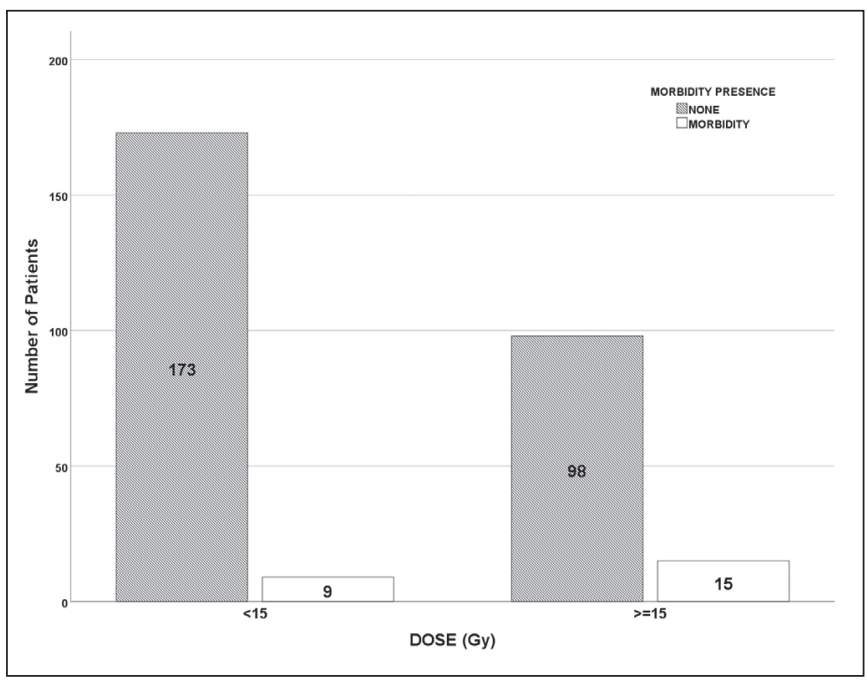

Figure 3: Chi-square test for morbidity and dose revealed significant difference. Patients who received doses higher than 15 Gy had more minor and major morbidity $(p=0.015)$. There were no differences in terms of morbidity between patients regarding age $(<65$ vs $>65)(p=0.707)$, tumor volume $\left(<4 \mathrm{~cm}^{3}\right.$ vs $\left.>4 \mathrm{~cm}^{3}\right)$ $(p=0.271)$, gender $(p>0.05)$ and tumor location $(p=0.478)$.

It was shown that tumor volume, location and treatment dose did not influence the progression of the tumors in all series and subgroups in multivariate statistical analysis. It was determined that total morbidity was higher in the patient group whose treatment dose was higher than $15 \mathrm{~Gy}$, compared to the patient group whose treatment dose was lower than 15 Gy (Figure 3).

\section{DISCUSSION}

Traditionally, surgical excision of meningioma has been accepted as gold standard treatment, and still has some important roles like histopathological sampling, decompression of surrounding neural parenchyma and vascular structures.

Although some authors still advocate for aggressive surgery, others prefer a more conservative approach involving subtotal resection which provides decrease of mass effect and protection of neurological function. This approach decreases morbidity and mortality (47). The recurrence rates after resection varies between $12-91 \%$ in different studies $(47,56)$.

The reported rates of gross-total resection (GTR) in skull base meningiomas (SBM) vary from $0 \%$ to $90 \%$; and the morbidity and mortality rates are as high as $67 \%(8,11,15,54,55,67)$. Some studies advocate that GTR is not possible in nearly $30 \%$ of cases because of critical locations like cavernous sinus, posterior fossa, petroclival region or optic nerve sheath $(31,33,36,44)$.

Even the subtotal or partial resection is associated with significantly high morbidity and mortatality rates, poor outcome is not rare (8). Some studies revealed that local progression rate of benign meningiomas after subtotal resection (STR) without adjuvant therapy may range between $37-62 \%$ in 5 years and $52-100 \%$ in 10 years $(3,10,35,58-60)$.
Petroclival, pontocerebellar, parasellar region and foramen magnum meningiomas represent the majority of the cases with high rates of morbidity and mortality $(2,8,16,52)$.

There is still debate about the optimal treatment of SBM. The high rate of morbidity makes many surgeons to prefer the maximal safe resection and adjuvant radiosurgery. This strategy has been a rational option to minimize the morbidity and mortality.

SRS has been a well-established treatment modality in meningiomas. SRS provides tumor control, and maintains neurological function (12). The majority of previous articles analyzed the role of SRS in both histologically confirmed and not confirmed WHO Grade I meningiomas.

As SRS offers high rates of tumor control and excellent outcomes, it becomes a first line treatment to prevent recurrences. Stereotactic radiosurgery preserves or improves neurological function in most of patients (9).

In our study, the tumor control rates and the morbidity rates after SRS treatment of 295 patients who were histopathologically diagnosed with WHO Grade 1 meningioma were evaluated. The tumor control rate in mean follow-up period of 54 months was $94.5 \%$.

Ganz et al. conducted a study and examined the results of SRS in meningiomas, and reported that the 12-16 Gy treatment dose was the ideal treatment interval in local tumor control (20). Also, Kondziolka et al. showed that the treatment doses over 15Gy did not have superiority to lower treatment doses (29). In our study, it was shown that the treatment dose had no effects on tumor control at all localizations as previous literature. However, statistical studies conducted previously show that the morbidity rates increased at the treatment doses above 15 Gy compared to patients below 15Gy. When the treatment dose is considered in SRS planning, taking this finding into consideration will decrease the morbidity risk after SRS.

In our study, it was shown that the tumor volume did not have any effects on the progression and postoperative morbidity risk after SRS. These findings show that SRS will be a proper treatment option following safe decompressive surgery by avoiding morbidity in meningioma surgeries with critical localizations. After eliminating the mass effect of the tumor, lesion-specific conservative surgery and adjuvant SRS treatment strategy (e.g. extracavernous resection and adjuvant SRS for residual tumor in parasellar region meningioma, subtotal resection in the parasagittal meningiomas, leaving the remnant tumor which invaded sagittal sinus and SRS for this lesion, in the meningioma localized posterior or inferior to IAC cranial nerve-protecting conservative subtotal resection and SRS) is the treatment approach to be preferred compared to the radical surgery, which will increase the risk of morbidity and mortality (Figure 4).

The "Follow-up and Wait-and-See" strategy after subtotal resection is the method that is preferred by many surgeons. Kim et al. conducted a study and compared 153 patients who received SRS in asymptomatic meningioma and 201 patients 


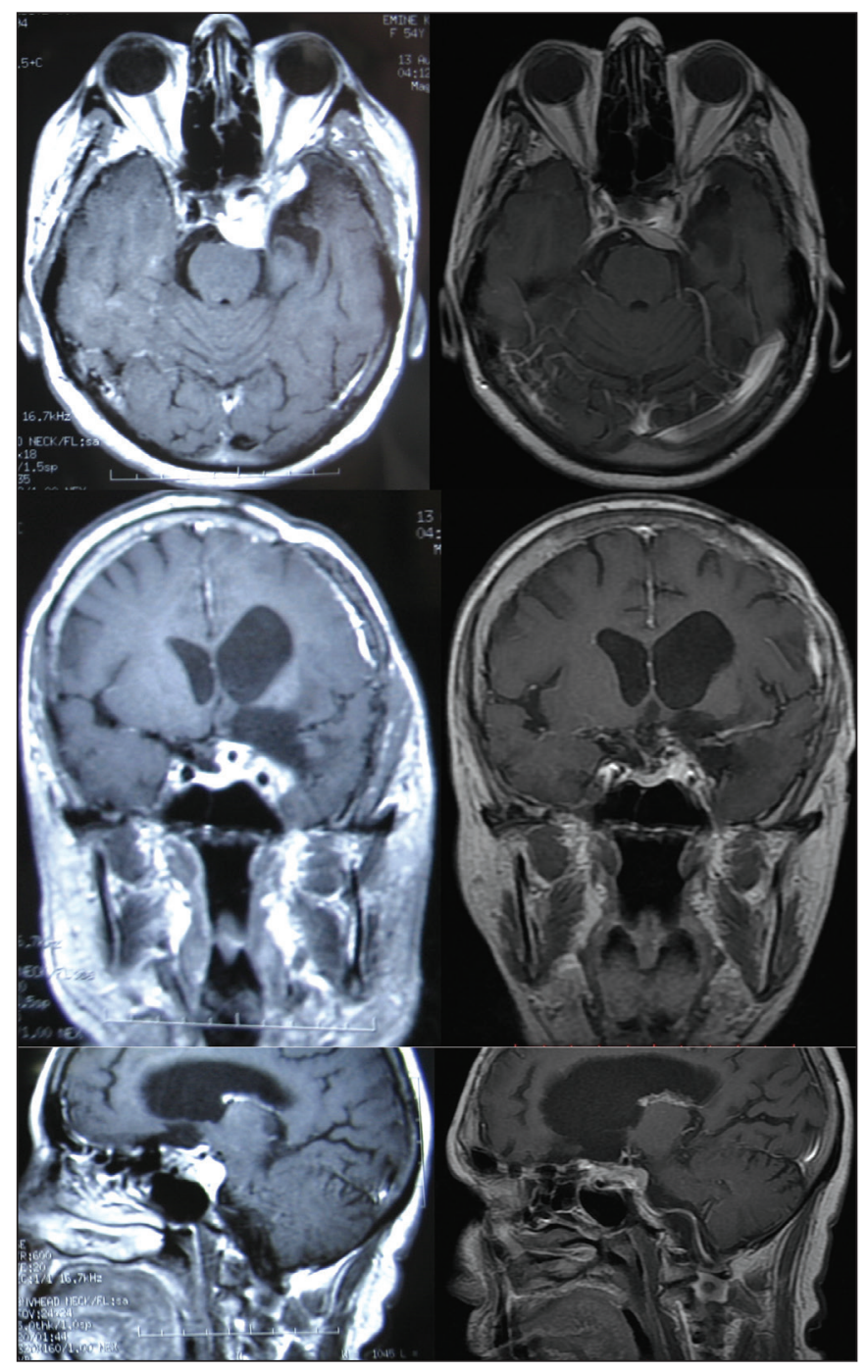

Figure 4: Illustrative case of a 54-year-old female patient with previous subtotal resection performed. Adjuvant SRS was performed. Residual tumor volume was $8.7 \mathrm{~cm}^{3}$, and treatment dose was 14 Gy. Pre- SRS (left side) and post- SRS (right side) T1-weighted contrast enhancement MRI shows decreased tumor volume after 96 months' follow-up.

who were not treated in their natural history. In the patients who received SRS in 5 years and 10 years, the PFS values were $98.7 \%$ and $92.9 \%$, respectively; however, in patients who were only followed-up, the PFS values were $38.5 \%$ and $7.9 \%$, respectively in 5 and 10 years. In this study, it was also shown that having no calcification, patients' being young, the presence of peritumoral edema and T2 hyperintensity were parameters that increased the risk of progression in the control group (26). When the superiority of the SRS over follow-up without treatment, which was shown in this study, and the tumor control rates of the adjuvant SRS in our study are considered, the adjuvant SRS should be considered instead of the Wait-and-See Strategy in meningiomas following the subtotal resection (26).
In our department, the surgical strategy in meningiomas is subtotal resection and adjuvant radiosurgery, if total resection seems to carry high risk for neurovascular structures (tumor adherence /invasion of critical structures).

Our treatment algorithm for progression after SRS is surgical removal is the first choice in these patients. But if a patient's comorbidities are high or the patient does not accept surgical treatment, SRS is the second option. But we also evaluate additional radiation-induced risk. If adverse radiation effect risk is high due to the first treatment (High dose or eloquent location) or the patient does not want to further treatment, we follow-up patients with radiological studies.

Sheehan et al. conducted a study with 736 meningioma patients; and shared their SRS results. They reported that having 1 surgery before SRS did not cause any statistical differences in the PFS compared to having surgery. However, in the same study, they also showed that the risk of regrowth of the tumor after SRS was more in the patients who had more than 1 surgery at a statistically significant level compared to patients who received 1 surgery (57). These findings made us consider the fact that $85(28.8 \%)$ of the patients in our study who had more than 1 surgery history before the SRS. These finding could explain the difference that was detected in the PFS rates compared to the literature.

\section{Parasellar Region Meningiomas}

Parasellar region meningiomas are challenging tumors for complete removal because of the close relationship with carotid artery and cranial nerves. GTR rate has been reported as $20-76 \%$, and morbidity rate has been reported as $16-74 \%$ $(13,15,42)$ in different studies.

SRS is an accepted treatment modality for parasellar region meningiomas both because of the poor surgical results and the high rate of tumor control with rarely occurring adverse effects. Kano et al. reported $94 \%$ PFS in 5 years and $86 \%$ in 10 years after SRS for cavernous sinus meningiomas. Kano et al. reported $92 \%$ cranial nerve deficits in patients with previous surgery and $84 \%$ in patients without previous surgery. SRS is associated with $20-29 \%$ neurological improvement in cavernous sinus meningiomas (23).

Pamir et al. compared radical surgery and conservative surgery together with adjuvant radiosurgery. This study showed that extracavernous resection of tumor and adjuvant SRS was as effective as radical surgery in terms of tumor control with low morbidity (43).

SRS provides $87-99 \%$ and $73-94 \%$ progression-free survival (PFS) rates, respectively in 5 and 10 years for cavernous sinus meningiomas $(40,45)$. The tumor control rates are greater than $90 \%(45)$.

In the presented series, there were 116 patients with meningiomas of sellar-parasellar and sphenoid ridge which had cavernous sinus invasion who had at least one prior surgery before SRS. The median tumor volume was $9 \mathrm{~cm}^{3}$ on median 56.4 months follow-up, local tumor control rate was $94.8 \%$. Major morbidity was detected in 3 of the patients (visual acuity decreased in 2 patients and radiation-induced necrosis occurred in 1 patient). 
Although all the meningiomas in this subgroup of patients were not located in cavernous sinus, the tumor control and morbidity rates were similar with the previous reports.

The documented success for tumor control and limited morbidity of radiosurgery for parasellar meningiomas helped to shift the surgical strategy from gross total resection to safe subtotal resection (27).

Pollack et al. analyzed 115 cavernous sinus meningiomas. A total of $40 \%$ of the pathologies of the patients was WHO Grade I meningioma which were confirmed histologically. Median follow-up was 89 months. A total of $5 \%$ patients had tumor growth after treatment. Tumor control rate was $99 \%, 93 \%$ in 5 years and 10 years, respectively. Tumor control rate was not statically associated with any factor; and $12 \%$ permanent morbidity was detected. Morbidity rate after treatment was associated with larger treatment volumes. New cranial nerve deficits occurred in $10 \%$ of the patients. The decrease in tumor volume was detected in $71 \%$ of the patients. Cranial nerve improvement was more frequent in patients with primary SRS $(41 \%)$ than in the patients with prior surgery (20\%) (45).

Many neurosurgeons advocate a more conservative surgical strategy, opting for subtotal resection to prevent the postoperative cranial neuropathies (16). Modern treatment strategies aim to preserve neurological function, reducing tumor volume if necessary and control tumor growth (27).

\section{Petroclival Meningiomas}

Petroclival meningioma originates from the medial of the skull base cranial nerve foramens and from the upper two-thirds of the clivus. Total resection is usually curable because most of the meningioma at this region has benign nature (WHO Grade I). However, aggressive surgery is usually associated with severe morbidity and mortality due to close relationship with cranial nerve, brain stem and vascular structures $(2,38,39)$.

Petroclival meningiomas tend to grow in their natural history. Tumor progression and clinical finding due to tumor growth was reported as $76 \%$ and $63 \%$, respectively (63). For this reason, Wait-and-See policy is not suitable in majority of petroclival meningiomas. Microsurgical and/or radiosurgical treatment should be considered for treatment.

Almefty et al. reported the surgical outcome of their petroclival meningioma series which had 64 patients. GTR can be achieved in $64 \%$ of patients. Tumor recurrence was significantly higher in cases with modified Kobayashi Grade III and IV than in Grade I and II. Overall 20\% recurrence was detected; and 9.8\% recurrence was found in cases with GTR. $\mathrm{CN}$ deficits were found in 42 patients; however, the risk was found to be lower in Grade I and II resected cases (1). Tumor recurrence risk is possible even after GTR because Simpson Grade 1 resection with dural attachment is usually not possible. Natarajan et al. reported the follow-up results of 48 total resected petroclival meningiomas. PFS rate was $100 \%$, $92.7 \%$ and $85 \%$ in 3, 7 and 12 years follow-up, respectively (39).

In a retrospective review of surgical series, the GTR rate was found in $49 \%$ of all the patients. New-onset neurological deficit after surgery was detected in $34 \%$ of the patients $(1,17)$. Although some neurosurgeons still recommend aggressive surgery for successful tumor control $(1,32)$, conservative approach with decompression of mass effect and adjuvant SRS also have favorable outcomes $(19,48)$.

Kim et al. compared SRS results for primary and adjuvant treatment. SRS was performed without surgical resection in 58 patients and postoperative in 31 patients. They accepted that increased tumor volume was more than $15 \%$ of pre-treatment tumor volume. The overall tumor control rate was reported as $94.4 \%$. Tumor control rates were found as $91.4 \%$ and $100 \%$ for primary SRS without surgical decompression and adjuvant SRS after surgery, respectively. Surgical decompression after adjuvant SRS was performed in 4 patients (because of cyst formation in 3 patients and tumor progression in 1 patient after SRS) (25).

Flannery et al. evaluated SRS outcomes in 168 petroclival meningioma. Local tumor control rate was $90 \%$. Neurological deterioration rate was $15 \%$. Adjuvant SRS was performed in 66 patients for Grade 1 meningiomas. Local tumor control and neurological deterioration was reported as $91 \%$ and $14 \%$, respectively in adjuvant SRS subgroup. Statistical analyses revealed that large pre-GKS tumor volume $\left(\geq 8 \mathrm{~mm}^{3}\right)$ is risk factor for progression and neurological deterioration in adjuvant SRS subgroup (19).

Our study demonstrated SRS outcomes after subtotal resection of Grade 1 petroclival meningioma. Local tumor control rate was $92.5 \%$. Our results suggest that more conservative surgical approach and adjuvant SRS is effective treatment options for petroclival meningiomas.

The reason of the lower rate of adverse radiation effect and other morbidities in this series may be the dose selection especially in petroclival meningiomas. In case of contact between the tumor and brain stem, we limit the dose to 13Gy. In other locations, we generally prefer 14 Gy margin dose if the tumor is not small. The dose selection strategy may also be the possible explanation for the low rate of PFS in the presented series. Although the tumor control rates are similar to the previous reports, tumor volume decrease is significantly low.

\section{Cerebellopontine Angle Meningiomas}

CPA meningiomas constitute $1 \%$ of meningiomas and $6 \%$ $15 \%$ of CPA tumors $(18,64)$. Total resection of CPA meningioma may be challenging because of close relationship with cranial nerves, vascular structures and adjacent brain stem. Chen at al. reviewed the literature for SBM and reported GTR as $82-86.1 \%$ and morbidity due to resection as $10.4-35.7 \%$ at cerebellopontine angle (8).

Recurrence of CPA meningiomas also depend on the extent of resection as in other locations (58). GTR without cranial nerve damage may be challenging especially in large or infiltrating CPA meningiomas.

Sekhar and Jannetta were pioneer surgeons for CPA tumors. They reported GTR rate as $64 \%$ in 22 CPA meningiomas. New-onset cranial nerve palsies were reported as $23 \%$ after surgery (53). 
Roser et al. reported $86 \%$ GTR, 14\% facial nerve palsy, and $23 \%$ hearing loss in 72 patients with CPA meningiomas (50). Surgical treatment of large posterior fossa meningiomas are associated with $46 \%$ complication rates, and GTR can be as low as $50 \%$ (18). Especially for large cerebellopontine meningiomas and petroclival tumors, the rates of morbidity increase and the total resection rates decrease in microsurgical treatment (18).

Nakamura et al. analyzed the effect of CPA meningioma relationship on the Internal Auditory Canal (IAC) on postoperative facial and vestibulocochlear nerve functional outcome. Superior location of tumor to the IAC has better facial and vestibulocochlear functional outcome after surgery (37). Also, Schaller et al. reported better facial and vestibulocochlear functional outcome after surgery for posteriorly-located CPA meningioma to the IAC than anteriorly-located meningioma to the IAC (51).

Ding et al. analyzed the results of SRS for CPA meningioma in 191 patients and reported PFS in 5 and 10 years as $93 \%$ and $77 \%$, respectively. Tumor control rate was $92 \%$ and deterioration in neurological function was detected in $8.5 \%$ of the patients. They reported $4 \%$ surgical resection after SRS because of symptomatic tumor growth and $1 \%$ ventriculoperitoneal shunt operation for hydrocephalus. Male gender was identified to be a bad prognostic factor for tumor control in this and previous series (18).

Starke et al. analyzed 152 posterior fossa meningiomas treated with SRS. Nearly half of the patients were treated after resection. The locations were as follows; $23 \%$ tentorial, $28 \%$ cerebellopontine angle, $18 \%$ petroclival, and $26 \%$ clivus. In 7 years of median follow-up $36 \%$ same tumor volume, $51 \%$ decrease in tumor volume and $13 \%$ increase in volume were detected. PFS in 3,5, 10 years were $98 \%, 96 \%$ and $78 \%$, respectively. They found that the older age and low dose to tumor margin were associated with tumor progression. A total of $91 \%$ of the patients were neurologically stable; and $5 \%$ edema and $9 \%$ worsening of the symptoms were detected. Worsening of the symptoms were more frequent in clivus and petroclival meningiomas. Posterior fossa meningiomas constitute $7 \%-12 \%$ of intracranial meningiomas. Total resection rates vary between $40 \%-96 \%$. Surgery is associated with $0 \%-13 \%$ morbidity and $13 \%-40 \%$ mortality. Previous history of surgery did not change recurrence rates (61).

Nicolato et al. found 95\% tumor control rate in 62 posterior fossa meningiomas treated with SRS. They reported $6.5 \%$ morbidity due to edema in the brain stem (41).

Successful tumor control rates and low morbidity rates of SRS have changed the treatment algorithm of CPA meningiomas. Maximal subtotal resection for decompression of the brain stem without cranial nerve and vascular damage and adjuvant SRS to residual lesion has been documented as safe and effective treatment option rather than aggressive surgery (18).

\section{Convexity, Parasagittal and Falcine Meningiomas}

Most of the convexity meningiomas are total-resectable with their dural attachment. However, in some patients, total resection is not possible because of the close relationship to the critical cortical part and cortical veins especially in elderly patients.

Although total resection should be the goal for convexity meningioma, Condra et al. reported the progression rate as $70 \%$ in subtotal resected convexity meningioma (10). Pollack et al. showed that SRS provide more successful tumor control rate compared with only subtotal resection. And they also stated that SRS has similar tumor control rate with Simpson Grade 1 resection (46).

Kondziolka et al. reported 125 patients with convexity meningioma treated with SRS. Half of the patients had previous surgery. In overall patients, $8 \%$ progression was detected after SRS with 6\% new neurological deficit. Tumor control rate was $97 \%$ in adjuvant SRS after subtotal resection of WHO Grade I meningioma subgroup. They hypothesized that irradiation of abnormal dura may be the underlying factor for SRS successful tumor control rate. In this study, SRS had similar tumor control with Simpson Grade 1 resection as previous studies (30).

Hasegawa et al. analyzed the SRS results for 108 meningiomas that were not located in skull base. A total of $59 \%$ of the patients had prior surgical resection; and in 72 months followup, $15 \%$ progression was detected in the cases. The rate of peritumoral edema was $50 \%$ in patients without prior surgery and $13 \%$ in patients with previous surgery (21).

Surgical strategy should be aggressive resection if possible in convexity meningioma. Tumor control rates of adjuvant SRS subtotal resected convexity meningiomas were worse than SBM that were resected subtotally. These findings suggest that convexity meningiomas are more radioresistant than SBM. Another hypothesis is about heterogeneous dose distribution of SRS. Radiation dose is decreased at the tumor margin compared with the center of the tumor (21).

Brain edema after SRS is much more common in convexity meningioma compared with SBM $(22,24,49)$. Rogers and Mehta reported the rate of cerebral edema after SRS in the SBM and other meningiomas as $0 \%-22 \%$ and $25 \%-78 \%$, respectively (49). Cai et al. found that the chance of edema after SRS increased $17 \%$ for each $1 \mathrm{~cm}^{2}$ increase in the tumorbrain interface (7). Pial blood supply has been associated with edema in meningiomas because of vascular endothelial growth factor secretion $(4,66)$. Parasagittal, convexity and falcine meningiomas have much more pial blood supply than SBMs, which are mostly surrounded with cisterns rather than brain parenchyma. For this reason, surgical resection and disruption of pial blood supply cause less post-SRS edema (28).

In our study, there were 80 patients with convexity, parasagittal or falcine meningiomas who had at least one surgery before SRS. The median tumor volume was $7.2 \mathrm{~cm}^{3}$ on median 54 months follow-up, local tumor control rate was $93.7 \%$ for this meningioma subgroup.

In this group, our treatment strategy is performing Simpson Grade 1 Resection as much as possible with aggressive surgery. 
If total resection cannot be carried out because of sagittal sinus invasion, neighboring eloquent area or neighboring critical vascular structure, our goal in surgery is providing maximum mass resection so as not to cause morbidity and mortality and to ensure maximum decompression and to disconnect the pial connections of the tumor. Cutting the pial connections interrupts the tumor-parenchyma neighborhood and allows that the dose of the neighboring brain parenchyma in radiosurgery decreases. In addition, this will also reduce the parenchymal edema risk after the SRS as mentioned before.

Minor morbidities were seen most frequently in this group. Two patients developed temporary edema; and 6 patients developed headache probably due to cerebral edema. These findings support the evidence that the risk of edema due to radiation is higher in patients with meningiomas that are convexity-localized compared to skull-based meningiomas after SRS. Major morbidity did not develop in this group.

\section{Limitations}

In our study, there were some limitations that stemmed from the characteristics that are specific to retrospective cohort analyses. The patient follow-up data and results were collected after a long time period following the radiosurgery. Our treatment doses and planning strategy changed through the 15 years, which included our study, as our radiosurgery experience increased. Although subtotal resection (Simpson Grade 4,5) was carried out in patients who were included in the study, the time between microsurgery and radiosurgery of the patients varied. Although all of the patients had received surgery before the SRS, some of the patients received more than 1 surgery because of recurrence. Radiosurgery and radiological systems improved in the follow-up period depending on the ever-developing technology. The Gamma Knife Model C was used in our clinic for SRS until 2013; and Perfexion was used as of 2013. However, this did not cause any statistically significant differences between these two periods.

\section{CONCLUSION}

SRS should not be considered as the first line treatment for lesions with mass effect requiring decompression. Safer microsurgical resection of meningiomas can be achieved by only debulking and leaving the critical parts of the tumor neighbor to cerebral arteries or important neural structures for radiosurgery. Safe decompression of critical structures like optic nerve and the brain stem, and leaving the remnant for stereotactic radiosurgery is also a rational treatment option.

\section{REFERENCES}

1. Almefty R, Dunn IF, Pravdenkova S, Abolfotoh M, AlMefty O: True petroclival meningiomas: Results of surgical management. J Neurosurg 120:40-51, 2014

2. Bambakidis NC, Kakarla UK, Kim LJ, Nakaji P, Porter RW, Daspit CP, Spetzler RF: Evolution of surgical approaches in the treatment of petroclival meningiomas: A retrospective review. Neurosurgery 62:1182-1191, 2008
3. Barbaro NM, Gutin PH, Wilson CB, Sheline GE, Boldrey EB, Wara WM: Radiation therapy in the treatment of partially resected meningiomas. Neurosurgery 20:525-528, 1987

4. Bitzer M, Wockel L, Luft AR, Wakhloo AK, Petersen D, Opitz $\mathrm{H}$, Sievert T, Ernemann U, Voigt K: The importance of pial blood supply to the development of peritumoral brain edema in meningiomas. J Neurosurg 87:368-373, 1997

5. Bondy M, Ligon BL: Epidemiology and etiology of intracranial meningiomas: A review. J Neuro-oncol 29:197-205, 1996

6. Borcek AO, Emmez H, Akkan KM, Ocal O, Kurt G, Aykol S, Karahaciogli E, Baykaner KM: Gamma Knife radiosurgery for arteriovenous malformations in pediatric patients. Child's Nervous System 30:1485-1492, 2014

7. Cai R, Barnett GH, Novak E, Chao ST, Suh JH: Principal risk of peritumoral edema after stereotactic radiosurgery for intracranial meningioma is tumor-brain contact interface area. Neurosurgery 66:513-522, 2010

8. Chen CM, Huang AP, Kuo LT, Tu YK: Contemporary surgical outcome for skull base meningiomas. Neurosurgical Review 34:281-296; discussion 296, 2011

9. Cohen-Inbar O, Lee CC, Sheehan JP: The contemporary role of stereotactic radiosurgery in the treatment of meningiomas. Neurosurgery Clinics of North America 27:215-228, 2016

10. Condra KS, Buatti JM, Mendenhall WM, Friedman WA, Marcus RB Jr, Rhoton AL: Benign meningiomas: Primary treatment selection affects survival. International Journal of Radiation Oncology, Biology, Physics 39:427-436, 1997

11. Couldwell WT, Fukushima T, Giannotta SL, Weiss $\mathrm{MH}$ : Petroclival meningiomas: Surgical experience in 109 cases. J Neurosurg 84:20-28, 1996

12. Day SE, Halasz LM: Radiation therapy for WHO grade I meningioma. Chinese Clinical Oncology 6:S4, 2017

13. De Jesus O, Sekhar LN, Parikh HK, Wright DC, Wagner DP: Long-term follow-up of patients with meningiomas involving the cavernous sinus: Recurrence, progression, and quality of life. Neurosurgery 39:915-919; discussion 919-920, 1996

14. Deltour I, Johansen C, Auvinen A, Feychting M, Klaeboe $\mathrm{L}$, Schuz J: Time trends in brain tumor incidence rates in Denmark, Finland, Norway, and Sweden, 1974-2003. Journal of the National Cancer Institute 101:1721-1724, 2009

15. DeMonte F, Smith HK, Al-Mefty O: Outcome of aggressive removal of cavernous sinus meningiomas. J Neurosurg 81:245-251, 1994

16. Di Maio S, Ramanathan D, Garcia-Lopez R, Rocha MH, Guerrero FP, Ferreira M Jr, Sekhar LN: Evolution and future of skull base surgery: The paradigm of skull base meningiomas. World Neurosurgery 78:260-275, 2012

17. Diluna ML, Bulsara KR: Surgery for petroclival meningiomas: A comprehensive review of outcomes in the skull base surgery era. Skull Base 20(5):337-342, 2010

18. Ding D, Starke RM, Kano H, Nakaji P, Barnett GH, Mathieu D, Chiang V, Omay SB, Hess J, McBride HL, Honea N, Lee JY, Rahmathulla G, Evanoff WA, Alonso-Basanta M, Lunsford LD, Sheehan JP: Gamma knife radiosurgery for cerebellopontine angle meningiomas: A multicenter study. Neurosurgery 75:398-408, 2014 
19. Flannery TJ, Kano H, Lunsford LD, Sirin S, Tormenti M, Niranjan A, Flickinger JC, Kondziolka D: Long-term control of petroclival meningiomas through radiosurgery. J Neurosurg 112:957-964, 2010

20. Ganz JC, Backlund EO, Thorsen FA: The results of Gamma Knife surgery of meningiomas, related to size of tumor and dose. Stereotactic and Functional Neurosurgery 61 Suppl 1:23-29, 1993

21. Hasegawa T, Kida Y, Yoshimoto M, lizuka H, Ishii D, Yoshida K: Gamma Knife surgery for convexity, parasagittal, and falcine meningiomas. J Neurosurg 114:1392-1398, 2011

22. Kalapurakal JA, Silverman CL, Akhtar N, Laske DW, Braitman LE, Boyko OB, Thomas PR: Intracranial meningiomas: Factors that influence the development of cerebral edema after stereotactic radiosurgery and radiation therapy. Radiology 204:461-465, 1997

23. Kano H, Park KJ, Kondziolka D, lyer A, Liu X, Tonetti D, Flickinger JC, Lunsford LD: Does prior microsurgery improve or worsen the outcomes of stereotactic radiosurgery for cavernous sinus meningiomas? Neurosurgery 73:401-410, 2013

24. Kim DG, Kim Ch H, Chung HT, Paek SH, Jeong SS, Han $\mathrm{DH}$, Jung HW: Gamma knife surgery of superficially located meningioma. J Neurosurgery 102 Suppl:255-258, 2005

25. Kim JW, Kim DG, Se YB, Kim SK, Chung HT, Paek SH, Jung HW: Gamma knife radiosurgery for petroclival meningioma: Long-term outcome and failure pattern. Stereotactic and Functional Neurosurgery 95:209-215, 2017

26. Kim KH, Kang SJ, Choi JW, Kong DS, Seol HJ, Nam DH, Lee $\mathrm{JI}$ : Clinical and radiological outcomes of proactive Gamma Knife surgery for asymptomatic meningiomas compared with the natural course without intervention. J Neurosurg, 2018 (Online ahead of print)

27. Klinger DR, Flores BC, Lewis JJ, Barnett SL: The treatment of cavernous sinus meningiomas: Evolution of a modern approach. Neurosurgical Focus 35:E8, 2013

28. Kollova A, Liscak R, Novotny J Jr, Vladyka V, Simonova G, Janouskova L: Gamma Knife surgery for benign meningioma. J Neurosurg 107:325-336, 2007

29. Kondziolka D, Flickinger JC, Perez B: Judicious resection and/or radiosurgery for parasagittal meningiomas: Outcomes from a multicenter review. Gamma knife meningioma study group. Neurosurgery 43:405-413; discussion 413-404, 1998

30. Kondziolka D, Madhok R, Lunsford LD, Mathieu D, Martin JJ, Niranjan A, Flickinger JC: Stereotactic radiosurgery for convexity meningiomas. J Neurosurgery 111:458-463, 2009

31. Levine ZT, Buchanan RI, Sekhar LN, Rosen CL, Wright DC: Proposed grading system to predict the extent of resection and outcomes for cranial base meningiomas. Neurosurgery 45:221-230, 1999

32. Li D, Hao SY, Wang L, Tang J, Xiao XR, Zhou H, Jia GJ, Wu Z, Zhang LW, Zhang JT: Surgical management and outcomes of petroclival meningiomas: A single-center case series of 259 patients. Acta Neurochirurgica 155:1367-1383, 2013

33. Mathiesen T, Lindquist C, Kihlstrom L, Karlsson B: Recurrence of cranial base meningiomas. Neurosurgery 39:2-7; discussion 8-9, 1996
34. Mawrin C, Perry A: Pathological classification and molecular genetics of meningiomas. J Neuro-oncol 99:379-391, 2010

35. Miralbell R, Linggood RM, de la Monte S, Convery K, Munzenrider JE, Mirimanoff RO: The role of radiotherapy in the treatment of subtotally resected benign meningiomas. $J$ Neuro-oncology 13:157-164, 1992

36. Mirimanoff RO, Dosoretz DE, Linggood RM, Ojemann RG, Martuza RL: Meningioma: Analysis of recurrence and progression following neurosurgical resection. J Neurosurg 62:18-24, 1985

37. Nakamura M, Roser F, Dormiani M, Matthies C, Vorkapic P, Samii M: Facial and cochlear nerve function after surgery of cerebellopontine angle meningiomas. Neurosurgery 57:77-90, 2005

38. Nanda A, Javalkar V, Banerjee AD: Petroclival meningiomas: Study on outcomes, complications and recurrence rates. J Neurosurgery 114:1268-1277, 2011

39. Natarajan SK, Sekhar LN, Schessel D, Morita A: Petroclival meningiomas: Multimodality treatment and outcomes at longterm follow-up. Neurosurgery 60:965-979; discussion 979981, 2007

40. Nicolato A, Foroni R, Alessandrini F, Maluta S, Bricolo A, Gerosa M: The role of Gamma Knife radiosurgery in the management of cavernous sinus meningiomas. International Journal of Radiation Oncology, Biology, Physics 53:992-1000, 2002

41. Nicolato A, Foroni R, Pellegrino M, Ferraresi P, Alessandrini F, Gerosa M, Bricolo A: Gamma knife radiosurgery in meningiomas of the posterior fossa. Experience with 62 treated lesions. Minimally Invasive Neurosurgery 44:211-217, 2001

42. O'Sullivan MG, van Loveren HR, Tew JM Jr: The surgical resectability of meningiomas of the cavernous sinus. Neurosurgery 40:238-244; discussion 245-237, 1997

43. Pamir MN, Kilic T, Bayrakli F, Peker S: Changing treatment strategy of cavernous sinus meningiomas: Experience of a single institution. Surgical Neurology 64 Suppl 2:S58-66, 2005

44. Pollock BE, Stafford SL, Link MJ: Gamma knife radiosurgery for skull base meningiomas. Neurosurgery Clinics of North America 11:659-666, 2000

45. Pollock BE, Stafford SL, Link MJ, Garces YI, Foote RL: Singlefraction radiosurgery of benign cavernous sinus meningiomas. J Neurosurg 119:675-682, 2013

46. Pollock BE, Stafford SL, Utter A, Giannini C, Schreiner SA: Stereotactic radiosurgery provides equivalent tumor control to Simpson Grade 1 resection for patients with small- to medium-size meningiomas. International Journal of Radiation Oncology, Biology, Physics 55:1000-1005, 2003

47. Przybylowski CJ, Raper DM, Starke RM, Xu Z, Liu KC, Sheehan JP: Stereotactic radiosurgery of meningiomas following resection: Predictors of progression. Journal of Clinical Neuroscience 22:161-165, 2015

48. Roche PH, Pellet W, Fuentes S, Thomassin JM, Regis J: Gamma knife radiosurgical management of petroclival meningiomas results and indications. Acta Neurochirurgica 145:883-888; discussion 888, 2003 
49. Rogers L, Mehta M: Role of radiation therapy in treating intracranial meningiomas. Neurosurgical Focus 23:E4, 2007

50. Roser F, Nakamura M, Dormiani M, Matthies C, Vorkapic P, Samii M: Meningiomas of the cerebellopontine angle with extension into the internal auditory canal. J Neurosurg 102:1723, 2005

51. Schaller B, Merlo A, Gratzl O, Probst R: Premeatal and retromeatal cerebellopontine angle meningioma. Two distinct clinical entities. Acta Neurochirurgica 141:465-471, 1999

52. Scheitzach J, Schebesch KM, Brawanski A, Proescholdt MA: Skull base meningiomas: Neurological outcome after microsurgical resection. J Neuro-oncol 116:381-386, 2014

53. Sekhar LN, Jannetta PJ: Cerebellopontine angle meningiomas. Microsurgical excision and follow-up results. J Neurosurg 60:500-505, 1984

54. Sekhar LN, Patel S, Cusimano M, Wright DC, Sen CN, Bank WO: Surgical treatment of meningiomas involving the cavernous sinus: Evolving ideas based on a ten year experience. Acta Neurochir Suppl 65:58-62, 1996

55. Sekhar LN, Wright DC, Richardson R, Monacci W: Petroclival and foramen magnum meningiomas: Surgical approaches and pitfalls. J Neuro-oncol 29:249-259, 1996

56. Sheehan JP, Starke RM, Kano H, Barnett GH, Mathieu D, Chiang V, Yu JB, Hess J, McBride HL, Honea N, Nakaji P, Lee JY, Rahmathulla G, Evanoff WA, Alonso-Basanta M, Lunsford LD: Gamma Knife radiosurgery for posterior fossa meningiomas: A multicenter study. J Neurosurgery 122:14791489, 2015

57. Sheehan JP, Starke RM, Kano H, Kaufmann AM, Mathieu D, Zeiler FA, West M, Chao ST, Varma G, Chiang VL, Yu JB, McBride HL, Nakaji P, Youssef E, Honea N, Rush S, Kondziolka D, Lee JY, Bailey RL, Kunwar S, Petti P, Lunsford LD: Gamma Knife radiosurgery for sellar and parasellar meningiomas: $A$ multicenter study. J Neurosurg 120:1268-1277, 2014
58. Simpson D: The recurrence of intracranial meningiomas after surgical treatment. Journal of Neurology, Neurosurgery, and Psychiatry 20:22-39, 1957

59. Soyuer S, Chang EL, Selek U, Shi W, Maor MH, DeMonte F: Radiotherapy after surgery for benign cerebral meningioma. Radiotherapy and Oncology 71:85-90, 2004

60. Stafford SL, Perry A, Suman VJ, Meyer FB, Scheithauer BW, Lohse CM, Shaw EG: Primarily resected meningiomas: Outcome and prognostic factors in 581 Mayo Clinic patients, 1978 through 1988. Mayo Clinic Proceedings 73:936-942, 1998

61. Starke RM, Nguyen JH, Rainey J, Williams BJ, Sherman JH, Savage J, Yen CP, Sheehan JP: Gamma Knife surgery of meningiomas located in the posterior fossa: Factors predictive of outcome and remission. J Neurosurg 114:1399-1409, 2011

62. Surawicz TS, McCarthy BJ, Kupelian V, Jukich PJ, Bruner JM, Davis FG: Descriptive epidemiology of primary brain and CNS tumors: Results from the central brain tumor registry of the United States, 1990-1994. Neuro-Oncology 1:14-25, 1999

63. Van Havenbergh T, Carvalho G, Tatagiba M, Plets C, Samii $\mathrm{M}$ : Natural history of petroclival meningiomas. Neurosurgery 52:55-62; discussion 62-54, 2003

64. Voss NF, Vrionis FD, Heilman CB, Robertson JH: Meningiomas of the cerebellopontine angle. Surgical Neurology 53:439-446; discussion 446-437, 2000

65. Wiemels J, Wrensch M, Claus EB: Epidemiology and etiology of meningioma. J Neuro-oncol 99:307-314, 2010

66. Yoshioka H, Hama S, Taniguchi E, Sugiyama K, Arita K, Kurisu $\mathrm{K}$ : Peritumoral brain edema associated with meningioma: Influence of vascular endothelial growth factor expression and vascular blood supply. Cancer 85:936-944, 1999

67. Zentner J, Meyer B, Vieweg U, Herberhold C, Schramm J: Petroclival meningiomas: Is radical resection always the best option? Journal of Neurology, Neurosurgery, and Psychiatry 62:341-345, 1997 